University of South Florida

DIGITAL COMMONS

Digital Commons @ University of

@ UNIVERSITY OF SOUTH FLORIDA

South Florida

Marine Science Faculty Publications

College of Marine Science

1996

\title{
Surface Manifestation of Internal Tides Generated Near Hawaii
}

Richard D. Ray

Hughes STX, NASA Goddard Space Flight Center

Gary T. Mitchum

University of South Florida, mitchum@usf.edu

Follow this and additional works at: https://digitalcommons.usf.edu/msc_facpub

Part of the Life Sciences Commons

\section{Scholar Commons Citation}

Ray, Richard D. and Mitchum, Gary T., "Surface Manifestation of Internal Tides Generated Near Hawaii" (1996). Marine Science Faculty Publications. 2082.

https://digitalcommons.usf.edu/msc_facpub/2082

This Article is brought to you for free and open access by the College of Marine Science at Digital Commons @ University of South Florida. It has been accepted for inclusion in Marine Science Faculty Publications by an authorized administrator of Digital Commons @ University of South Florida. For more information, please contact digitalcommons@usf.edu. 


\title{
Surface manifestation of internal tides generated near Hawaii
}

\author{
Richard D. Ray \\ Hughes STX, NASA Goddard Space Flight Center, Greenbelt, Maryland
}

Gary T. Mitchum

Department of Marine Science, University of South Florida, St. Petersburg, Florida

\begin{abstract}
Analysis of Topex/Poseidon satellite altimetry reveals short-wavelength fluctuations in the ocean surface tide that are attributable to internal tides. A significant fraction of the semidiurnal internal tide generated at the Hawaiian Ridge is evidently phase-locked to the astronomical potential and can modulate the amplitude of the surface tide by $\sim 5 \mathrm{~cm}$. The internal tide is thus easily mapped along satellite groundtracks, and it is found to be spatially coherent over great distances, with waves propagating well over $1000 \mathrm{~km}$ from the Hawaiian Ridge before decaying below noise level. Both first and second baroclinic modes are observed in both the $\mathbf{M}_{2}$ (lunar) and $\mathrm{S}_{2}$ (solar) tides. The high space-time coherence is in sharp contrast to what is often inferred from current-meter observations, but it confirms recent speculations from an acoustic experiment north of Hawaii.
\end{abstract}

\section{Introduction}

Linear hydrodynamic theory characterizes two general features of the tidal motion in a stratified ocean: a primary surface wave that is "barotropic," with horizontal current velocities independent of depth, and internal waves that are "baroclinic," with horizontal currents displaying vertical shear but with relatively little surface elevation. The ocean's barotropic tide is driven by the gravitational forcing of the moon and sun and is therefore predictably regular. The baroclinic tide is known to be generated when the barotropic tide is impeded.by large bathymetric features such as the continental shelf or mid-ocean ridge. As changes in temperature and salinity modify ocean density or background oceanic currents, the characteristics of baroclinic waves also vary, and observations have given us a picture of internal tides highly incoherent in both time and space [Wunsch, 1975].

Internal tides may be observed by any number of instruments that sample within the water column, but owing to their relatively small surface effects, they are less easily observed from above. Occasionally some unique surface property reveals them: for example, patches of enhanced surface roughness or reflectivity, a dramatic (though strictly nonlinear) example being satellite images of long-crested, tidally generated solitons [Osborne and Burch, 1980]. Surface mea-

Copyright 1996 by the American Geophysical Union.

Paper number 96GL02050

0094-8534/96/96GL-02050\$05.00 surements at island tide gauges often display slightly broadened line spectra (tidal "cusps"), which have been attributed to the small, superimposed surface motions of time-varying internal tides [Radok et al., 1967]. Mitchum and Chiswell (in prep.) show this mechanism at work in an array of tide gauges along the northern coasts of the Hawaiian Islands. We show here that satellite altimetry, which acts as a kind of global tide gauge, may now be added to this list of observational techniques.

Vertical tidal motions of the thermocline (or other surfaces such as the pycnocline) are quite commonly observed with amplitudes of ten or more meters. Chiswell [1994] reports amplitudes of 15 meters at $23^{\circ} \mathrm{N}, 158^{\circ} \mathrm{W}$, just north of Hawaii. An internal tide of this amplitude is expected, very roughly, to have surface amplitudes reduced by the effective gravity ratio, which is typically of order $10^{-3}$ [Apel, 1987], implying likely surface effects of a few $\mathrm{cm}$. This is within the resolvability of modern satellite altimetry.

\section{Analysis of Altimetry}

The U.S.-French Topex/Poseidon satellite altimeter [Fu et al., 1994], launched in August 1992, repeatedly measures the sea-surface elevation of points along a fixed groundtrack every 9.9 days. These data have been used by several groups to map the large-scale features of the global ocean tide to unprecedented accuracy [e.g., Le Provost, Bennett, and Cartwright, 1994; see also the several papers in the Topex/Poseidon special issue of J. Geophys. Res., Dec. 15,1994 .] We stress "large-scale": only by combining data from a number of neighboring groundtracks have investigators overcome the aliasing problems inherent in sampling diurnal and semidiurnal tides at a 10-day period [Parke et al., 1987; Schrama and Ray, 1994]. To observe at the small spatial scales of internal tides, however, we are restricted to tidal analyses at individual points along the groundtrack. Fortunately, we now have a sufficiently long time series of altimeter observations-approximately three years-that such small-scale analyses may be attempted. Three years, in fact, is the minimum timespan for safely separating the major $\mathbf{M}_{2}$ and $S_{2}$ tides, which are closely aliased to periods of 62.1 and 58.7 days, respectively. (Other aliasing problems remain, however; for example, $K_{1}$ and Ssa remain inseparable for timespans less than 9 years.)

Partly owing to the intriguing results recently obtained in the acoustic experiment of Dushaw et al. [1995] as well as the evident surface detection of the internal tide at Hawai- 


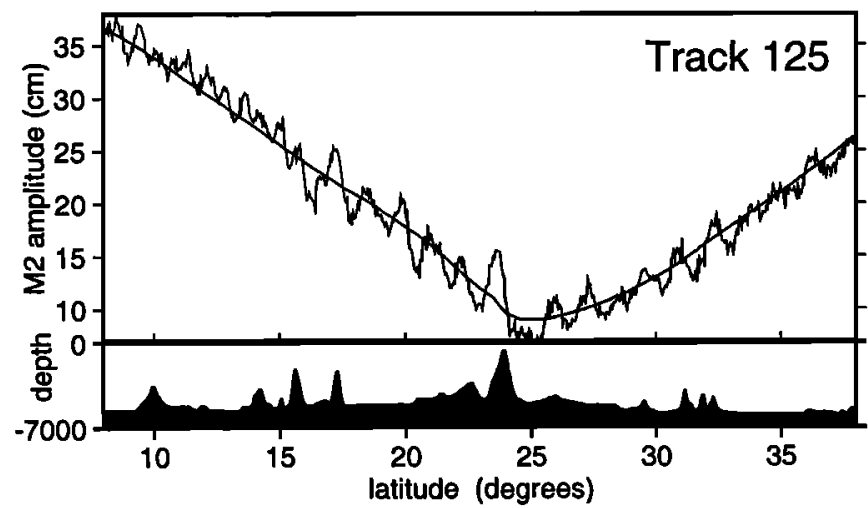

Fig. 1. Ragged line: $M_{2}$ tidal amplitudes estimated every 5.75 $\mathrm{km}$ along Topex/Poseidon track 125 , from approximately three years of collinear differenced data, using the response method of analysis [Cartwright and Ray, 1990]. (Harmonic analysis yields similar results.) Standard errors for all estimates are approximately $1 \mathrm{~cm}$. Smooth line: $\mathbf{M}_{2}$ tidal amplitudes from the (updated) $0.5^{\circ}$ global model of Schrama and Ray [1994]; another recent Topex model (CSR3.0 of R. J. Eanes) gives nearly identical results. The bathymetric profile is extracted from a 5-minute public domain database (TerrainBase) of global topography. Track location can be seen in Figure 5.

ian tide gauges by Mitchum and Chiswell, we have concentrated on an area of the Pacific Ocean surrounding the Hawaiian Island chain and undersea ridge. An additional benefit of this area is that the $\mathbf{M}_{2}$ surface tide propagates into the region from the north northeast [e.g., Le Provost et al., 1994] and impinges upon the ridge roughly perpendicularly, while Topex/Poseidon ascending tracks transect the ridge also nearly perpendicularly, thus providing simplified sampling and analysis of generated waves. What follows is primarily a descriptive summary of what is found in the altimetry.

The results of performing tidal analyses of the data along Topex track 125 shows clear oscillations in the estimated $\mathrm{M}_{2}$ amplitudes (Figure 1; refer to Figure 5 for the location of this track). For reasons that follow, we interpret these oscillations to be the small $($ several $\mathrm{cm}$ ) surface effects of phase-locked internal tides propagating off various topographic features, primarily the Hawaiian ridge. The sea surface expression of the internal waves alternately add con-



Fig. 2. High-pass filtered output of the tidal amplitudes of Figure 1 , along with the corresponding filtered amplitudes of $S_{2}$ (offset). Filter is of Gaussian type with width $450 \mathrm{~km}$.

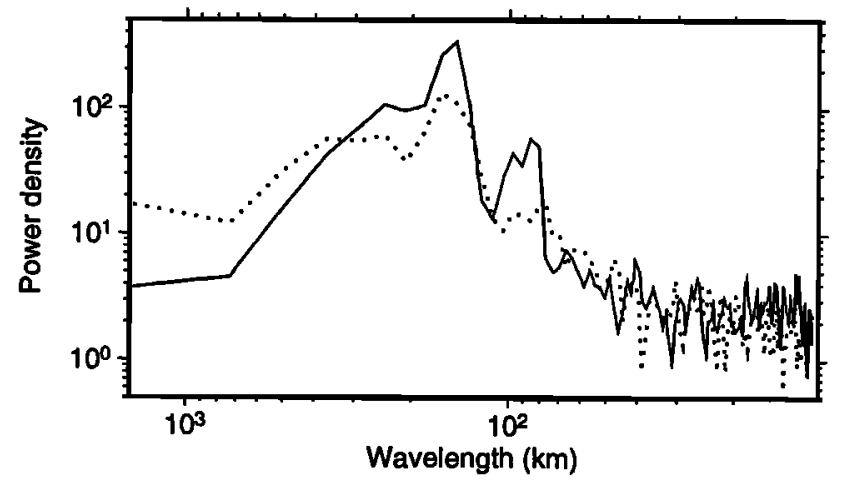

Fig. 3. Power spectrum of the data in Figure 2. Solid line is for $\mathbf{M}_{2}$, dashed line for $S_{2}$. The peaks occur close to the expected wavelengths of first and second baroclinic modes for these semidiurnal tides.

structively or destructively to the sea surface expression of the barotropic tide, resulting in the oscillatory amplitudes shown. The oscillations are obviously "phase-locked" with the astronomical potential by definition of our tidal analysis; incoherent waves would average out and remain undetected.

The $S_{2}$ tide shows similar features, although it is understandably noisier owing to smaller overall amplitudes. Comparison of high-pass filtered $\mathbf{M}_{2}$ and $\mathrm{S}_{2}$ amplitudes (Figure 2) shows the largest oscillation occurs at the ridge, with a trough slightly to the north of the ridge peak and a large crest directly to the south. This identical geometrical relationship to the ridge is consistent with both constituent waves being generated there; the two wavetrains then drift apart owing to the natural dispersion of internal tides and to the likely interference from multiple sources.

Spectral analysis of the $M_{2}$ and $S_{2}$ wavetrains of track 125 (Figure 3) reveals two peaks at approximate wavelengths $\left(\lambda_{1}, \lambda_{2}\right)=(150,85) \pm 10 \mathrm{~km}$ for $M_{2},(160,80) \pm 20 \mathrm{~km}$ for $S_{2}$. Assuming that wave propagation occurs parallel to the satellite groundtracks, these values give quite reasonable agreement with the theoretically expected wavelengths of the first

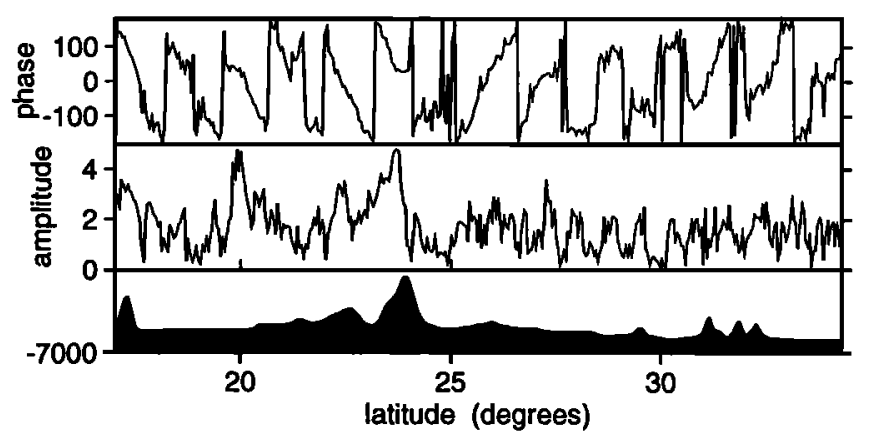

Fig. 4. Amplitudes (cm) and phase lags (degrees) of the "residual" tidal signal along track 125 , obtained after high-pass filtering both in-phase and quadrature components of the original estimated tidal solutions. In general, the phase lags imply wave propagation away from the Hawaiian Ridge. Amplitudes south of the ridge are very complex, but, as noted in text, there are probably multiple sources there. 
and second baroclinic modes. Based on CTD surveys at $40^{\circ} \mathrm{N}$, Dushaw et al. [1995] calculated expected wavelengths of $(156,76) \mathrm{km}$ for $\mathbf{M}_{2},(147,72) \mathrm{km}$ for $S_{2}$. Similar CTD data at $23^{\circ} \mathrm{N}$, discussed by Chiswell [1994], imply firstmode wavelengths of $140 \mathrm{~km}$ and $134 \mathrm{~km}$ for $M_{2}$ and $S_{2}$, respectively. It is a curious feature of track 125 that the second baroclinic mode appears more pronounced (relative to the first mode) in the southern section of the track; theory predicts that the second mode decays more rapidly with distance from the source, but since the topography south of Hawaii is complex, these second modes are possibly locally produced.

Confirmation that most of the observed oscillations are indeed progressive waves propagating away from Hawaii can be determined from additional phase information in the tidal solutions. Figure 4 shows the amplitudes and phase lags of a "residual" tide, obtained after removing the barotropic (i.e. a complex, low-pass filtered) signal. In such diagram, wave propagation northward (or southward) is indicated by phase lags increasing (or decreasing) with latitude, while standing waves are indicated by nearly constant phase lags with $180^{\circ}$ jumps when the amplitudes drop to zero. The general trend in Figure 4 clearly suggests propagation away from the Hawaiian Ridge. One curious exception is the interval $28^{\circ} \mathrm{N}$ $-30^{\circ} \mathrm{N}$ where a standing wave pattern is evident.

Interestingly, the increased amplitudes evident near $20^{\circ} \mathrm{N}$ are not far from Horizon Guyot $\left(19^{\circ} \mathrm{N}, 169^{\circ} \mathrm{W}\right)$, where $\mathrm{No}$ ble et al. [1988], based on current-meter measurements, conjectured that a large phase-locked internal tide is present. They suggested that the tide is generated locally, partly because of the presumed unlikelihood of a far-field internal

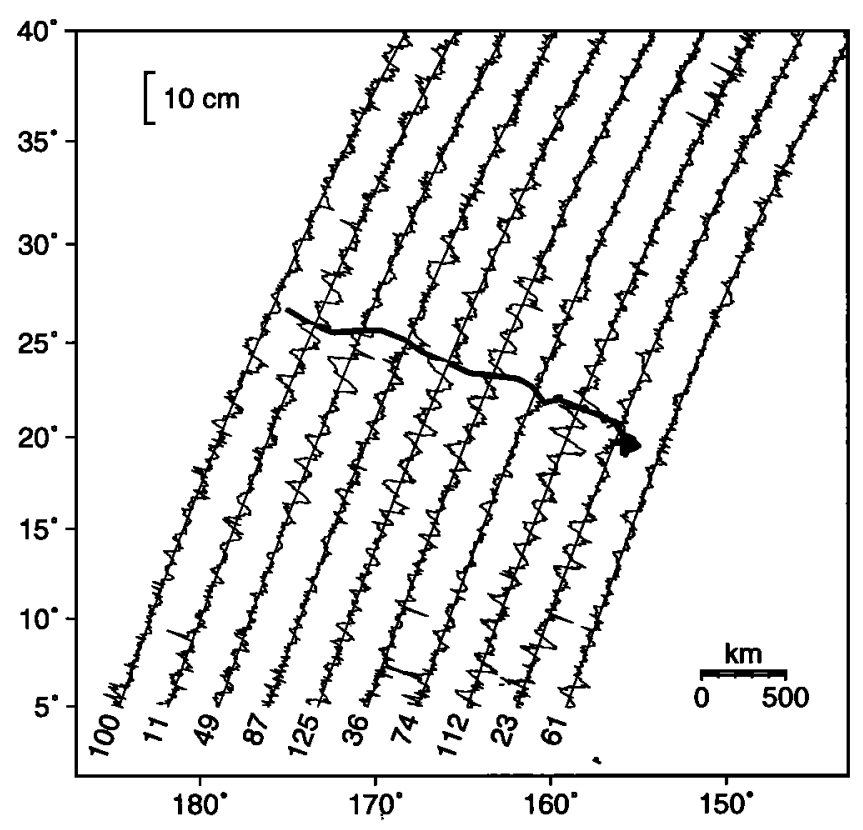

Fig. 5. High-pass filtered $M_{2}$ amplitudes plotted along 10 ascending Topex/Poseidon tracks. The bold line represents the approximate location of the Hawaiian Ridge crest. Track labels, referred to in the text, are along bottom of chart. Amplitude scale bar in upper left. See also color plate on this issue's cover. tide remaining phase-locked for the duration of their measurements (nine months). Our phase observations (Figure 4) show strong continued southward propagation throughout this region. Although there is clearly local interference and distortion, the waves generated at the Hawaiian ridge are apparently capable of propagating well beyond $19^{\circ} \mathrm{N}$.

Figure 5 (see also the cover of this issue) shows in map form the high-pass filtered $\mathbf{M}_{2}$ amplitudes for all ascending Topex tracks across the Hawaiian ridge. The oscillations are evident throughout the area. An identical generation mechanism along all tracks is suggested by the following observation: Along all eight interior tracks, a trough is consistently observed over the northern flank of the ridge, except for tracks 87 and 23 where the trough shifts to the center of the ridge, but for these two tracks the ridge is considerably wider; the pattern is missing for track 74 , but for this track the ridge is broken up and the ocean considerably deeper. Perhaps the most striking feature of the map is the longrange coherence of the waves: propagation both northwards and southwards from the ridge is apparent for well over 1000 $\mathrm{km}$. This along-track coherence is clear; less clear is the cross-track coherence. Yet it is easy to trace, say, the third peak north of the ridge across the eight interior tracks and to show that the traced wavecrest is at least as straight as the ridge itself. Beyond that distance (about $400 \mathrm{~km}$ ), the wavecrest begins to break up in sections, yet in other places propagation continues to the very edge of the map.

A precise (1/e) decay distance is thus not easily determined in the face of obvious multiple sources and interference; the drop in amplitude south of the ridge as seen in Figure 4 suggests perhaps $300 \mathrm{~km}$ (neglecting the likely role of secondary sources having caused this drop), while Figure 5 suggests distances considerably greater than $1000 \mathrm{~km}$. In fact, any decay scale inferred from Figure 5 could be considered a lower bound on the scale for an individual wavetrain, since small variations in propagation speed, while having little effect on the phase lock at short distances, will accumulate over larger distances, generating possible cancellation unrelated to real dissipation.

Exactly how internal tides in the open ocean are dissipated is far from clear, but suggested mechanisms include internal turbulent friction, vertical shear stress, wave breaking, and nonlinear interactions between the internal tides and the rest of the internal wave spectrum [Wunsch, 1975]. Theories based on internal turbulence [Rattray, 1957; LeBlond, 1966] have predicted decay scales of $10^{3}-10^{4} \mathrm{~km}$. LeBlond's estimated $Q$ of order 15, which is comparable to the estimated $Q$ of the barotropic semidiurnal tide [Cartwright and Ray, 1991], is not inconsistent with the decay lengths observed here. A similar $Q$ could result, of course, from other dissipative mechanisms.

\section{Discussion and Summary}

We may summarize our results by emphasizing the two aspects of coherence - time and space - that contradict our received notions about the behavior of internal tides. First, 
there is a persistent component of internal tides that remains phase-locked to the barotropic tide over a period of three years. It is manifested by a modulation in the surface tide by as much as $5 \mathrm{~cm}$. The persistence is surprising in light of many mooring observations [e.g. Radok et al., 1967; Magaard and McKee, 1973] that show internal tides to be highly variable, if not practically intermittent, in some locations, although Wunsch [1975] points out that some of this perceived intermittency may be caused by the low signal-to-noise ratio prevalent in in situ tidal current and temperature measurements. Indeed, Hendry [1977] found that nearly $50 \%$ of the internal tidal variance was coherent with the astronomical tide in a region of the northwest Atlantic. And, as mentioned above, Noble et al. [1988] observed a baroclinic tide at Horizon Guyot that was phase-locked over a period of 9 months. The degree of coherence is undoubtedly location dependent; both our study and Hendry's are near prime generation areas for internal tides.

A second important point is that this phase-locked component remains spatially coherent over great distances. This again contrasts with some mooring observations that have shown little spatial coherence between internal-tide measurements [e.g., Barnett and Bernstein, 1975]. But our results confirm the work of Dushaw et al. [1995] who, on the basis of a reciprocal acoustic tomography experiment north of Hawaii, conjectured that there is a phase-locked internal tide, most likely generated at Hawaii and propagating to at least $40^{\circ} \mathrm{N}$, the northern boundary of their acoustic array.

Of course, natural temporal variations in the oceanic medium ensure substantial variability in internal tides, a fact confirmed by many in situ measurements. Mitchum and Chiswell (in prep.) discuss the time-variability in terms of its effect on the surface tide at Hawaiian tide gauges. They find that variability (interannual and intra-annual) induces a modulation in the $\mathbf{M}_{2}$ amplitude of about 1 to $2 \mathrm{~cm}$, so it is apparently smaller than the phase-locked component of the tide studied here.

Acknowledgments. We thank D. E. Cartwright and G. D. Egbert for several useful discussions of this work.

\section{References}

Apel, J. R., Principles of Ocean Physics, Academic Press, London, 1987.

Barnett, T. P. and R. L. Bernstein, Horizontal scales of midocean internal tides, J. Geophys. Res., 80, 1962-1965, 1975.
Cartwright, D. E. and R. D. Ray, Oceanic tides from Geosat altimetry, J. Geophys. Res., 95, 3069-3090, 1990.

Cartwright, D. E. and R. D. Ray, Energetics of global ocean tides from Geosat altimetry, J. Geophys. Res., 96, 16897-16912, 1991.

Chiswell, S. M., Vertical structure of the baroclinic tides in the central North Pacific subtropical gyre, J. Phys. Oceanogr., 24, 20322039, 1994.

Dushaw, B. D., B. D. Cornuelle, P. F. Worcester, B. M. Howe, D. S. Luther, Barotropic and baroclinic tides in the central North Pacific Ocean determined from long-range reciprocal acoustic transmissions, J. Phys. Oceanogr., 25, 631-647, 1995.

Fu, L.-L., E. J. Christensen, C. A. Yamarone, M. Lefebvre, Y. Ménard, M. Dorrer, P. Escudier, Topex/Poseidon mission overview, J. Geophys. Res., 99, 24369-24381, 1994.

Hendry, R. M., Observations of the semidiurnal internal tide in the western North Atlantic Ocean, Phil. Trans. R. Soc. Lond., A286, 1-24, 1977.

LeBlond, P. H., On the damping of internal gravity waves in a continuously stratified ocean, J. Fluid Mech., 25, 121-142, 1966.

Le Provost, C., A. F. Bennett, D. E. Cartwright, Ocean tides for and from Topex/Poseidon, Science 267, 639-642, 1995.

Magaard L. and W. D. McKee, Semi-diurnal tidal currents at Site D, Deep-Sea Res., 20, 997-1009, 1973.

Noble, M., D. A. Cacchione, W. C. Schwab, Observations of strong mid-Pacific internal tides above Horizon Guyot, J. Phys. Oceanogr., 18, 1300-1306, 1988.

Osborne, A. R. and T. L. Burch, Internal solitons in the Andaman Sea, Science, 208, 451-457, 1980.

Parke, M. E., R. H. Stewart, D. L. Farless, D. E. Cartwright, On the choice of orbits for an altimetric satellite to study ocean circulation and tides, J. Geophys. Res., 92, 11693-11707, 1987.

Radok, R., W. Munk, J. Isaacs, A note on mid-ocean internal tides, Deep-Sea Res., 14, 121-124, 1967.

Rattray, M., Propagation and dissipation of long internal waves, Trans. Am. Geophys. Union, 38, 495-500, 1957.

Schrama, E. J, O. and R. D. Ray, A preliminary tidal analysis of Topex/Poseidon altimetry, J. Geophys. Res., 99, 24799-24808 1994.

Wunsch, C., Internal tides in the ocean, Rev. Geophys. Space Phys., 13, 167-182, 1975.

G. T. Mitchum, Dept. Marine Science, University of South Florida, St. Petersburg, FL 33701

R. D. Ray, HSTX, NASA/GSFC, Code 926, Greenbelt, MD 20771; ray@nemo.gsfc.nasa.gov

(received May 8, 1996; accepted June 6, 1996.) 